\title{
Strain induced augmentation of upper oesophageal sphincter pressure in children
}

\author{
J Willing, Y Furukawa, G P Davidson, J Dent
}

\begin{abstract}
The hypothesis that troublesome oesophagopharyngeal reflux arises from defective upper oesophageal sphincter response to straining has been evaluated in 53 children aged two to 81 months (median 13) referred with symptoms thought to be related to gastro-oesophageal reflux. Spontaneously occurring pharyngeal, upper oesophageal sphincter, oesophageal body, and gastric pressures were analysed after feeding. Inspiratory strain was the most common spontaneously occurring strain (172 episodes), defined as an oesophageal body inspiratory negative pressure dip at least twice the size of the normal inspiratory wave. Overall, during inspiratory strain, upper oesophageal sphincter pressure was significantly higher than before straining $(\mathrm{p}<0.01)(5 v 27$ $\mathrm{mm} \mathrm{Hg}, \mathrm{p}<0 \cdot 01$ ). Sustained strains defined as increases in gastric and oesophageal body pressure for two to 20 seconds were also common (149 episodes) and when compared with just before straining, also augmented upper oesophageal sphincter pressure $(60 v 39$ $\mathrm{mm} \mathrm{Hg}, \mathrm{p}<0.01)$. The vigour of straining, estimated as increase of gastric pressure, correlated significantly with the degree of augmentation of upper oesophageal sphincter pressure $(\mathbf{p}<0.05)$. Children with and without evidence of troublesome oesophagopharyngeal reflux showed no difference in upper oesophageal sphincter response patterns to straining. Failure of augmentation of upper oesophageal sphincter tone in the face of strain induced increases of oesophageal body pressure is probably a secondary factor in the production of oesophagopharyngeal reflux in children.
\end{abstract}

(Gut 1994; 35: 159-164)

Gastroenterology Unit, Adelaide Children's Hospital, Adelaide, South Australia

J Willing

G P Davidson

Department of Surgery,

Jikei University School of

Medicine, Tokyo, Japan

Y Furukawa

Gastroenterology Unit, Royal Adelaide Hospital,

Adelaide, South Australia

J Dent

Correspondence to:

Dr G P Davidson,

Gastroenterology Unit,

Adelaide Children's Hospital,

King William Road, North

Adelaide, South Australia

5006.

Accepted for publication

28 June 1993
Gastro-oesophageal reflux is an important paediatric problem, which can result in significant complications such as failure to thrive, oesophagitis, and respiratory disease. It is believed that the upper oesophageal sphincter (UOS) has a major role in the prevention of oesophagopharyngeal reflux, an important contributing factor to the complications of gastro-oesophageal reflux.

Several mechanisms have been proposed for the occurrence of oesophagopharyngeal reflux episodes. The prevailing concept is that refluxate escapes from the oesophagus because of a defective steady state tone of the UOS. Our previous studies have not supported this as we have shown that in children UOS tone is well maintained during gastro-oesophageal reflux and is also augmented by increases in the level of arousal. ${ }^{12}$ A second possibility is that oesophagopharyngeal reflux could occur because of transient reflex relaxations of the UOS. These have been shown to occur in adults ${ }^{3}$ and children. ${ }^{2} \mathrm{~A}$ third possibility, which forms the basis of this paper, is that the UOS has an inadequate reflex contraction in response to the challenge of strain induced increases of oesophogeal body pressure.

Children strain frequently when crying, coughing or defecating; but the effect of straining on their UOS function is unknown. In one study in adults, reported only in abstract form, straining has been shown to cause augmentation of UOS pressure. ${ }^{4}$ In this study we have investigated the adaptive responses of the UOS to straining and have tested whether children with clinical oesophagopharyngeal reflux have defective responses to straining.

\section{Patients and methods}

PATIENTS

Fifty three children aged two to 81 months (median 13) were enrolled in the study. The patients were referred to the gastroenterology unit of the Adelaide Children's Hospital for evaluation of symptoms thought to be a result of gastro-oesophageal reflux or a feeding disorder. All children were fully assessed clinically by GPD or one other consultant paediatric gastroenterologist. The study protocol was approved by the research ethics committee of the Adelaide Children's Hospital. Informed parental consent was obtained before the study.

The Table gives the classification of major presenting symptoms and incidence of neurological dysfunction in the 53 children in whom technically satisfactory UOS recordings were obtained. The patients were subdivided into those with clinical evidence of oesophagopharyngeal reflux (vomiting, failure to thrive) and those with various other symptom patterns, but no evidence of oesophagopharyngeal reflux (other groups see Table). Neurological dysfunction was defined by the presence of symptoms and signs of cerebral palsy or developmental delay confirmed by the Denver developmental screening test. ${ }^{5}$

\section{Major presenting symptoms}

\begin{tabular}{lll}
\hline & \multicolumn{2}{l}{ Noof patients } \\
\cline { 2 - 3 } & $\begin{array}{l}\text { Without } \\
\text { neurological } \\
\text { deficit }\end{array}$ & $\begin{array}{l}\text { With } \\
\text { neurological } \\
\text { deficit }\end{array}$ \\
\hline Symptom group & 29 & 9 \\
\hline Vomiting/failure to thrive & 27 & 5 \\
Irritability/abdominal pain & 8 & 3 \\
Recurrent respiratory disease/apnoea & 8 & 2 \\
Food refusal/swallowing dificulties & 8 & 9 \\
\hline
\end{tabular}

Some patients presented with more than one major symptom. 
PROTOCOL

Dual sleeve manometric assemblies were used for concurrent monitoring of lower oesophageal sphincter (LOS) and UOS pressures. Assemblies were passed transnasally without the aid of sedation after a three hour fast. After positioning of a $\mathrm{pH}$ electrode and manometric assembly (see later) the child was allowed to settle and was then fed appropriately for age with formula or nonacid food such as sandwiches and milk. Monitoring of spontaneous patterns of motility and oesophageal $\mathrm{pH}$ was started at the end of the meal and continued for four hours with the children recumbent and unsedated.

\section{RECORDING TECHNIQUE}

The technique used has been described by us previously.' In brief, one of two dual sleeve perfused manometric assemblies was used to monitor UOS and lower oesophageal sphincter (LOS) pressures concurrently to satisfy the need for clinical evaluation of LOS function. The two assemblies had different intersleeve distances to cope with the range of intersphincteric distances found in this age group. Six sideholes monitored gastric, oesophageal body, and pharyngeal pressures.

For clinical purposes distal oesophageal $\mathrm{pH}$ was monitored concurrently with a miniature intraluminal monopolar glass electrode (Microelectrodes Inc, New Hampshire, USA, model MI-506) and a skin electrode was used as a reference (Micro-electrodes Inc, New Hampshire, USA, model MI-402). The results for $\mathrm{pH}$ monitoring do not form part of this study and will not be presented.

The position of the manomentric $\mathrm{pH}$ recording assembly was adjusted to give monitoring of both UOS and LOS pressures. If the spacing of the sleeves did not permit this, only LOS pressure was monitored to provide the necessary clinical evaluation.

\section{DATA ANALYSIS}

The tracings were scanned for the presence of short duration strains. Up to 10 episodes of each strain type were analysed in each patient, in order of occurrence. In most children there were fewer than 10 strains of each type in the entire tracing that were suitable for analysis. Any events that were a combination of any of the four type of strains were excluded.The complex patterns of strains seen during crying were also not analysed. To remove the possibility of interference of UOS or oesophageal body pressures by swallowing, strains were analysed only if there was at least one second free of swallowing after the strain, and at least six seconds free of swallowing or secondary oesophageal body peristalsis before the onset of the strain (Fig 1). The reference point for timing of swallows was taken from the onset of the abrupt pharyngeal pressure spike. The reference pressure used for determining UOS pressure before, during, and after strains was basal end expiratory oesophageal body pressure.

Four types of strain were analysed:

Inspiratory strains (Fig 2), were identified from
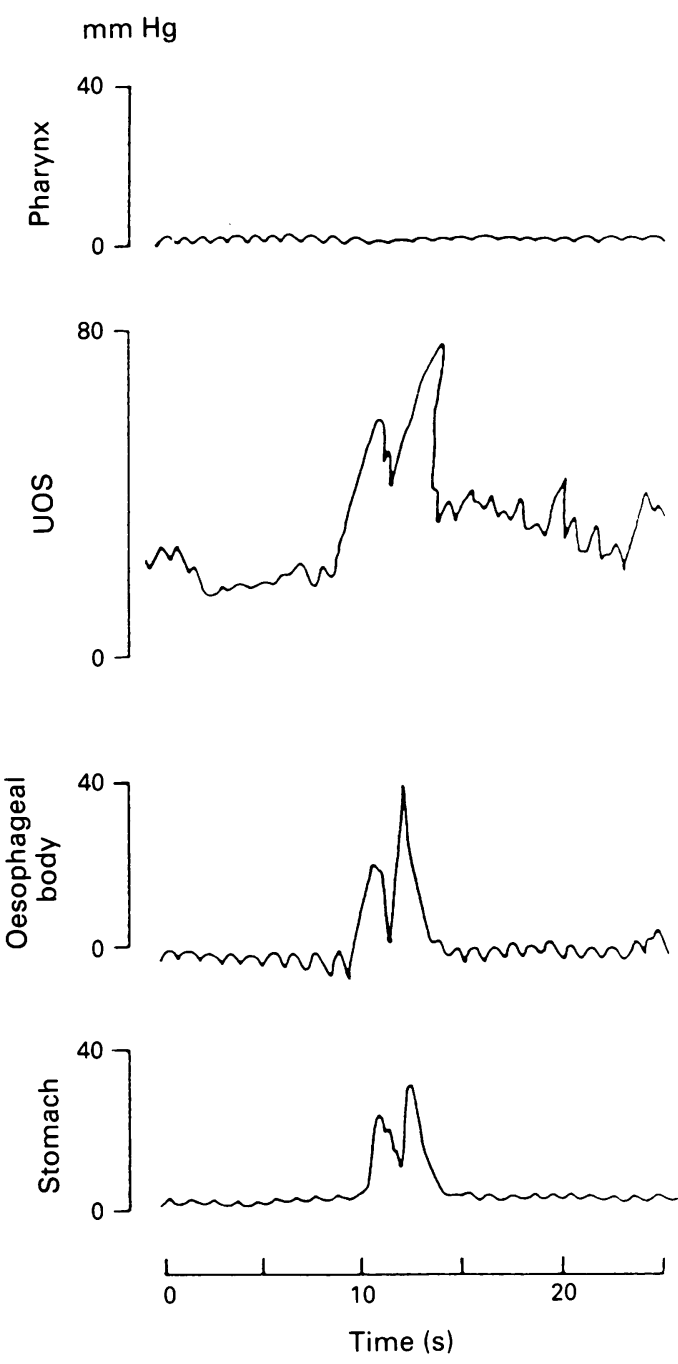

Figure 1: Manometric tracing of pharyngeal, upper oesophageal sphincter (UOS), oesophageal body, and gastric pressures in one of the study children. A sustained strain is associated with augmented UOS pressure.

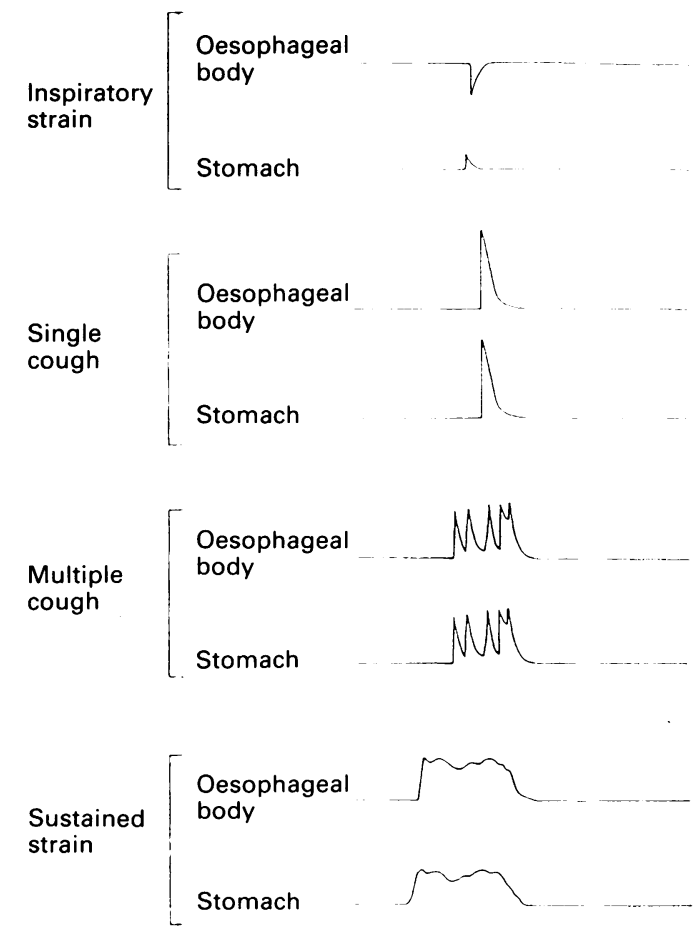

Figure 2: Diagrammatic illustration of the patterns of straining that were analysed. 
the oesophageal body tracing as inspiratory pressure dips at least twice the size of the normal excursion, which were at least $10 \mathrm{~mm} \mathrm{Hg}$ below end expiratory oesophageal body pressure. To ensure that the strain was primarily inspiratory, any associated subsequent positive expiratory pressure wave had to be less than $5 \mathrm{~mm} \mathrm{Hg}$ above the usual end expiratory pressure during quiet respiration. Any inspiratory pressure dips less than 0.5 seconds in duration were excluded from the analysis. UOS pressure was read at the time of the nadir of oesophageal pressure generated by inspiration for both the strain itself and for the three respiratory cycles before and after the strain. The change in gastric pressure was measured.

Sustained strains (Fig 2), were identified as gastric pressure increases to more than $5 \mathrm{~mm} \mathrm{Hg}$ above basal end expiratory gastric pressure for 2 to 20 seconds, which had a corresponding rise in oesophageal body pressure. Peak gastric and oesophageal body pressures were determined over the period of the strain. Strain duration was taken as the time that gastric pressure was at least $5 \mathrm{~mm} \mathrm{Hg}$ above basal end expiratory gastric pressure. UOS pressure was measured during the strain and for up to 10 seconds before and after the strain in two second intervals by visual mean. The times over which pressures were evaluated before and after straining were determined by the occurrence of swallowing (see first paragraph, data analysis).

Single cough strains (Fig 2), were identified as spike like gastric pressure increases, above 40 $\mathrm{mm} \mathrm{Hg}$ and not longer than 1.5 seconds, which had temporally associated abrupt positive pressure waves in the oesophageal body tracing. The UOS pressure was measured at the time of the peak of the strain; basal end expiratory UOS pressure was also determined for three respira-

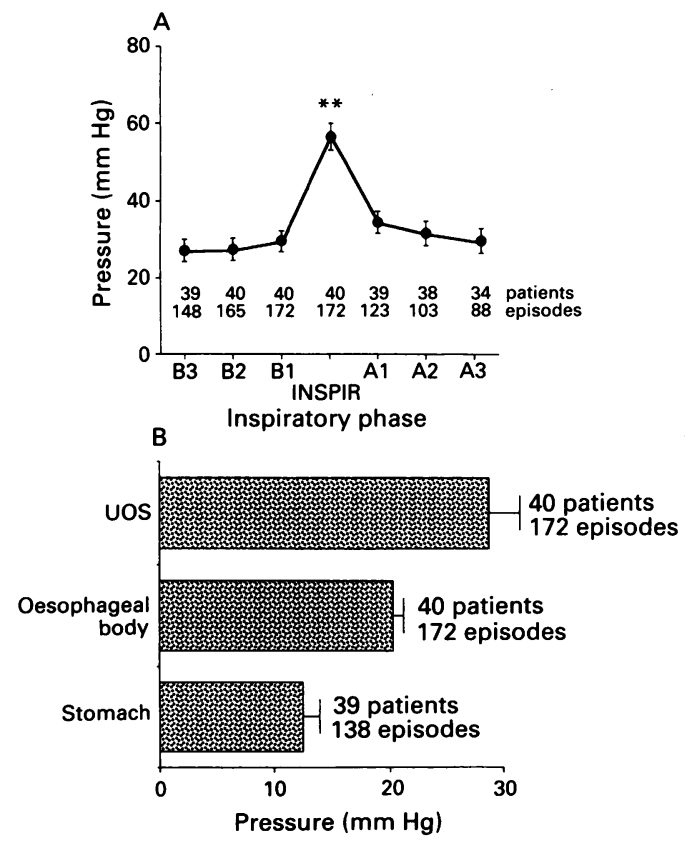

Figure 3: Inspiratory strains. (A) Mean upper oesophageal sphincter (UOS) pressure before, during, and after inspiratory straining. $\left({ }^{\star \star} p<0.01\right.$ for comparison with before strain pressure); (B) peak changes of pressure during straining in the UOS, oesophageal body, and stomach referenced to basal pressures just before straining. tory cycles before and after the strain. The vigour of coughing was assessed by measurement of the peak oesophageal body pressure at the time of the strain.

Multiple cough strains (Fig 2), were identified from the gastric pressure tracing when three or more single cough strains (see above) occurred within three seconds of each other. Strain associated peak gastric and oesophageal body pressures were measured and strain duration taken as the time over which gastric pressure exceeded the baseline by $5 \mathrm{~mm} \mathrm{Hg}$. Mean UOS pressure was determined visually in two second intervals during the total period of multiple coughing and for up to 10 seconds before and after the strain, the interval evaluated being determined by the occurrence of swallowing (see first paragraph, data analysis).

\section{STATISTICAL ANALYSIS}

Pressures within each strain or subdivision were compared by constructing a correlation matrix. Levels of significance were then recorded. Differences between the groups with and without oesophagopharyngeal reflux were examined using Student's $t$ test.

\section{Results}

We analysed 172 inspiratory strains in 40 patients, 149 sustained strains in 34 patients, seven single cough strains in six patients, and 35 multiple cough strains in 14 patients. There were five patients with no analysable episodes of straining of any type.

\section{INSPIRATORY STRAINS}

Figure 3A shows UOS pressures before, during, and after the strain. UOS pressure was significantly higher $(p<0.01)$ during the strain than before or after the strain. Figure 3B shows the typical changes in gastric, oesophageal body, and UOS pressure during straining. There was no significant correlation between UOS pressure change and either oesophageal body or gastric pressure change during straining.

\section{SUSTAINED STRAINS}

The mean (SD) duration of the strains was 5.6 $(0 \cdot 4)$ seconds, range 2-18 seconds. Figure 4 shows the UOS, gastric, and oesophageal body pressures before, during, and after the strain. UOS pressure was significantly higher during the strain than before $(p<0.01)$ or after $(p<0.01)$ the strain. Figure 5 shows the significant correlation between the increases of UOS pressure and those of gastric $(p<0.05)$ and oesophageal body pressures $(\mathrm{p}<0.05)$.

\section{MULTIPLE COUGH STRAINS}

The duration of the 35 strains ranged from 2-12 seconds. UOS pressure was significantly higher during $(\mathrm{p}<0.05)$ and after $(\mathrm{p}<0.01)$ the strain compared with before the strain (Fig 6A). Figure 6B shows the peak increases in gastric, oesophageal body, and UOS pressure during strains. 
Figure 4: Sustained strains. (A) Mean upper oesophageal sphincter (UOS) pressure sustained straining $(\star \star p<0 \cdot 01$ for comparisons with before strain pressure); (B) peak pressure increases during straining for the stomach referenced to basal pressures just before straining. before, during, and after $U O S$, oesophageal body and

SINGLE COUGH STRAINS

Mean UOS pressure from the seven evaluable episodes was not significantly different $(p>0.05)$ during the strain compared with before or after the strain, though there was a trend toward higher UOS pressures during the strain. There was no significant correlation between changes of
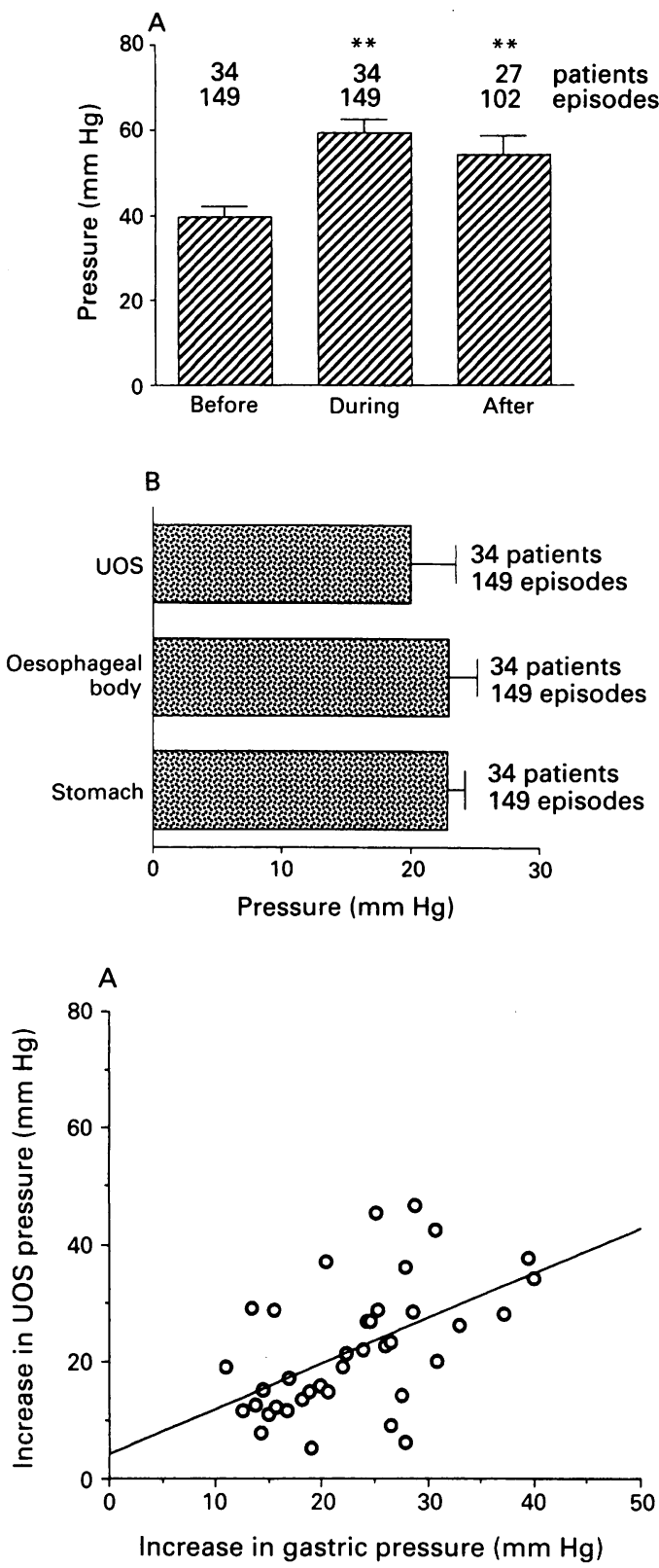

Figure 5: (A) Correlation of the change in gastric pressure with the change in upper oesophageal sphincter (UOS) pressure during sustained straining $(p<0.05) ;(B)$ correlation of the change in oesophageal pressure with the change in UOS pressure during sustained straining $(p<0.05)$.

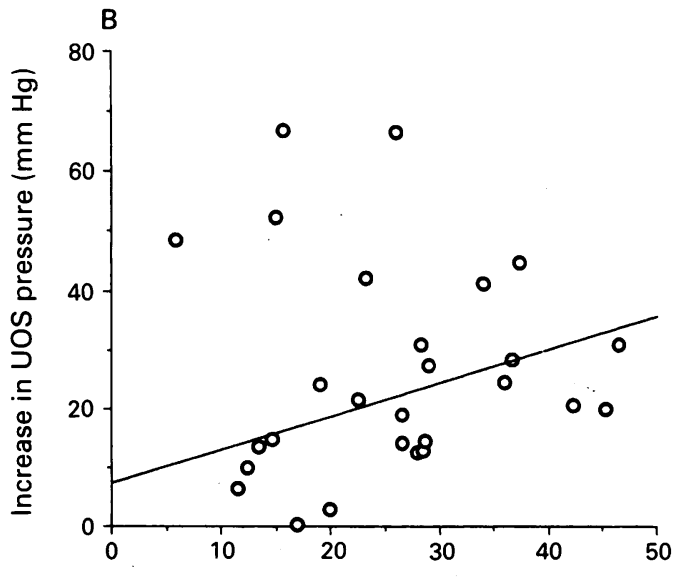

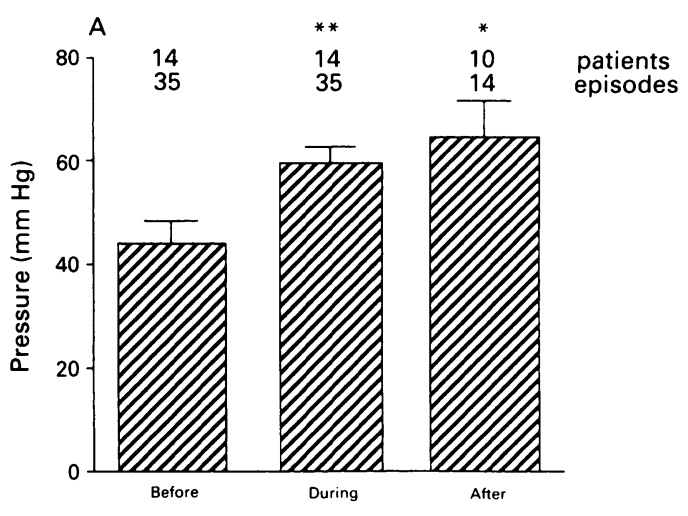

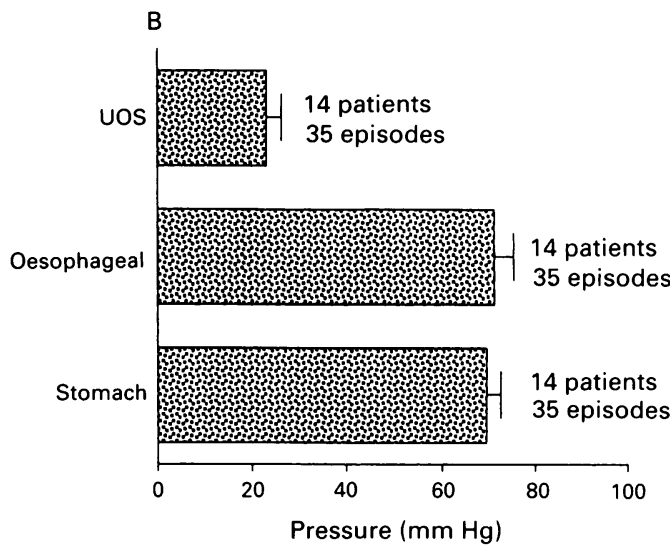

Figure 6: Multiple cough strains. (A) Mean upper oesophageal sphincter (UOS) pressure before, during, and after multiple cough straining. $\left({ }^{\star} p<0.05, \star \star p<0.01\right.$ for comparisons with before strain pressures); (B) peak pressure increases during straining in the UOS, oesophageal body, and stomach referenced to basal pressures just before straining.

UOS pressure and oesophageal body or gastric pressure.

\section{UOS PRESSURE AND SYMPTOM GROUPS}

During sustained straining, UOS pressure (mean (SD)) was significantly higher $(\mathrm{p}<0.01)$ in the group with oesophagopharyngeal reflux $(68.2(14.7) \mathrm{mm} \mathrm{Hg}, \mathrm{n}=17)$ than in the group without oesophagopharyngeal reflux $(50.6(20 \cdot 2)$ $\mathrm{mm} \mathrm{Hg}, \mathrm{n}=17)$. No difference was found between the groups for the magnitude of UOS augmentation for the other strain types. Presence or absence of neurological impairment had no discernable influence on UOS straining responses.

Discussion

The evaluations reported in this study aimed at assessing if defective responses to straining could be a cause of oesophagopharyngeal reflux. We have established for the first time that physical straining in children is consistently associated with a substantial and simultaneous increase in UOS pressure. The analysis of patient subgroups shows that these straining responses are preserved in all groups.

The straining induced augmentation of UOS pressure occurs synchronously with the strain and seems to be of sufficient magnitude to maintain a pressure barrier between the lumen of the oesophageal body and pharynx. Maintenance 
of this pressure barrier was shown with our recording methods despite the fact that the sleeve has a limited capacity to record abrupt increases in sphincter pressure because of its compliance. ${ }^{6}$ This compliance probably partly obscured any dose response relation of the magnitude of straining and the magnitude of the UOS pressure response, especially for short duration strains. This probably explains why the dose response relation was most firm for sustained straining (Fig 5).

We elected to analyse four different patterns of straining. Because these were spontaneous strains they had to be standardised using somewhat arbitrary definitions derived from changes of both intrathoracic pressure and intragastric pressure. The second was used as an indicator of intraperitoneal pressure changes. Evaluation of spontaneous episodes is the only feasible approach in children of the age that we studied, and had the advantage of analysis of naturally occurring events. The timings and relations between intrapleural and intraperitoneal pressures show that there are several generic patterns of straining. Probably the most important grouping of strain patterns is where there is a simultaneous increase in intra-abdominal and intrathoracic pressure, such as occurs during coughing or during body movement associated with partial or complete glottic closure. In the other important pattern of straining, produced by deep inspiration and consequently an open glottis, there is a larger than normal inspiratory decrease of intrathoracic pressure, associated with an increase of intra-abdominal pressure. Such straining would not be expected to challenge the barrier function of the UOS. Our data show that either pattern of straining is associated with abrupt augmentation of UOS pressure. This is similar to findings from a study of nine normal adult volunteers. ${ }^{7}$

There are three main mechanisms that might account for the occurrence of oesophagopharyngeal reflux episodes. Firstly, oesophagopharyngeal reflux may result from sustained failure of maintenance of any form of pressure barrier because of defective basal UOS tone; no such defect has been identified in limited studies in children. ${ }^{12}$ Secondly, oesophagopharyngeal reflux could occur during periods of transient reflex inhibition of the UOS. It has been shown that such inhibition occurs in response to oesophageal distension in both adults ${ }^{3}$ and children, ${ }^{2}$ and that this is the mechanism for venting of gas from the oesophageal body. ${ }^{38}$ There are no data, however, that examine whether this is the mechanism of oesophagopharyngeal reflux. The third possibility, evaluated in this study, was that oesophagopharyngeal reflux episodes might result primarily because of partial or complete failure of adaptive tightening during stress on the anti-reflex function of the UOS by a straining induced increase in intrathoracic pressure. Our data show that there is UOS pressure augmentation during straining, which occurs in all children regardless of whether or not they have symptoms indicative of oesophagopharyngeal reflux. In fact, the group of children with clinical indications of oesophagopharyngeal reflux showed a higher UOS pressure during sustained straining than those without oesophagopharyngeal reflux. This may be because of an increase in the level of arousal when the UOS is potentially threatened by oesophagopharyngeal reflux. Our data cannot explore the possibility that in any child there may be an intermittent failure of response to straining, which might then permit occurrence of oesophagopharyngeal reflux. The possibility of such a 'trip up' of sphincter function can only be answered by recording of events during episodes of oesophagopharyngeal reflux.

The mechanics of the UOS resemble most closely those of the anal sphincter. In both sphincters their external aspects are removed from the pressure environment of the peritoneal or thoracic cavities. Pressures from these cavities are, however, transmitted to the sphincter lumen. Consequently, the normally accurately timed augmentations of external anal sphincter contraction are important for maintenance of anal continence during straining. The rapidity of these external anal sphincter responses to straining depend upon this component being composed of striated muscle. The patterns of UOS function we have recorded are analagous to the anal sphincter. The UOS consists of striated muscle and is capable of very abrupt augmentations of pressure during periods of increased levels of mental arousal, ${ }^{1}$ and during straining, as shown in this study.

It could be argued that the strain associated augmentation of UOS pressure that we have found in the present analysis could be solely because of mental arousal and not because of the strain itself, as we have shown that such arousal augments UOS pressure.' Undoubtedly, many episodes of straining are associated with increased mental arousal and so this factor must contribute to the effects we have seen. Our data suggest though, that strain in itself is important, because the UOS pressure augmentation in response to inspiratory straining only occurred during the single inspiration. It is most unlikely that mental arousal could have produced such a discrete response.

Our analysis makes it unlikely that oesophagopharyngeal reflux episodes occur mainly because of consistent failure of strain induced UOS responses. It should not be assumed that oesophagopharyngeal reflux occurs by only one mechanism. Little reward has come from attempts to deduce the mechanical events responsible for sphincter incompetence from sampling of basal sphincter pressure, from testing with standardised stressors of sphincter function, or from various in vitro models of sphincter function and dysfunction. The best way for increasing our knowledge of the mechanisms that control oesophagopharyngeal reflux is to measure the events occurring during oesophagopharyngeal reflux with a technique that permits precise resolution of the timing and relation between UOS pressure, straining, and oesophagopharyngeal reflux. Only in this way will the responsible factors be recognised.

This work was supported by a project grant from the National Health and Medical Research Council of Australia. We thank Drs WDA Ford, T Pouras, and DJ Moore for referring their patients to us. 
1 Davidson GP, Dent J, Willing J. Monitoring of upper oesophageal sphincter pressure in children. Gut 1991; 32: 607-11.

Willing J, Davidson GP, Dent J, Cook I. Effect of gastrooesophageal reflux on upper oesophageal sphincter motility in

3 Kahrilas PJ, Dodds WJ, Dent J, Wyman JB, Hogan WJ, Arndorfer RC. Upper eosophageal sphincter function during belching. Gastroenterology 1986; 91: 113-40.

4 Anvari M, Dent J, Waterfall WE, Cook I, Invari P. Motor responses of the upper eosophageal sphincter to physical straining. Gastroenterology 1987; 92: A1297.
5 Frankenburg WK, Dodds JB. The Denver developmental screening test. $\mathcal{F}$ Pediatr $1967 ; 71: 181$

6 Dent J. A new technique for continuous sphincter pressure measurement. Gastroenterology 1976; 71: 263-7.

7 Anvari $M$, Cook I, Dent J, Anvari P, Waterfall WE. Protection of airways from oesophago-pharyngeal reflux during physical straining. Gastroenterology 1991; 100: A415.

8 Shaker R, Dodds WJ, Hogan WJ, Arndorfer RC, Hofmann C, Dent J. Mechanisms of esophago-pharyngeal reflux and regurgitation. Gastroenterology 1990; 100: A494. 